Article

\title{
Long Noncoding RNA PVT1 Is Regulated by Bromodomain Protein BRD4 in Multiple Myeloma and Is Associated with Disease Progression
}

\author{
Hiroshi Handa ${ }^{1, *} \mathbb{0}$, Kazuki Honma ${ }^{2}$, Tsukasa Oda ${ }^{3}$, Nobuhiko Kobayashi ${ }^{1}$, Yuko Kuroda ${ }^{2}$, \\ Kei Kimura-Masuda ${ }^{2}$, Saki Watanabe ${ }^{2}$, Rei Ishihara ${ }^{2}$, Yuki Murakami ${ }^{2}$, Yuta Masuda ${ }^{2}$, \\ Ken-ichi Tahara ${ }^{1}$, Hisashi Takei ${ }^{1}$, Tetsuhiro Kasamatsu ${ }^{2}{ }^{\mathbb{D}}$, Takayuki Saitoh ${ }^{2}$ and \\ Hirokazu Murakami ${ }^{2}$ \\ 1 Department of Hematology, Gunma University Graduate School of Medicine, 3-39-22 Showa-machi, \\ Maebashi, Gunma 371-8511, Japan; nobuhiko.kobayashi@gmail.com (N.K.); kenichit3@gmail.com (K.-i.T.); \\ m14702054@gunma-u.ac.jp (H.T.) \\ 2 Department of Laboratory Science, Gunma University Graduate School of Health Science, \\ 3-39-22 Showa-machi, Maebashi, Gunma 371-8511, Japan; m12203035@gunma-u.ac.jp (K.H.); \\ m14711022@gunma-u.ac.jp (Y.K.); kei-masuda@gunma-u.ac.jp (K.K.-M.); m13203040@gunma-u.ac.jp (S.W.); \\ m13203005@gunma-u.ac.jp (R.I.); m13203034@gunma-u.ac.jp (Y.M.); yuuken.0420@gmail.com (Y.M.); \\ kasamatsu@gunma-u.ac.jp (T.K.); tsaitoh@gunma-u.ac.jp (T.S.); hmura@gunma-u.ac.jp (H.M.) \\ 3 Institute of Molecular and Cellular Regulation, Gunma University, 3-39-22 Showa-machi, Maebashi, \\ Gunma 371-8511, Japan; toda@gunma-u.ac.jp \\ * Correspondence: handahiroshi@gunma-u.ac.jp; Tel.: +81-27-220-8166; Fax: +81-27-220-8173
}

Received: 3 August 2020; Accepted: 24 September 2020; Published: 27 September 2020

\begin{abstract}
Long noncoding RNAs (lncRNAs) are deregulated in human cancers and are associated with disease progression. Plasmacytoma Variant Translocation 1 (PVT1), a lncRNA, is located adjacent to the gene MYC, which has been linked to multiple myeloma (MM). PVT1 is expressed in MM and is associated with carcinogenesis. However, its role and regulation remain uncertain. We examined PVT1/MYC expression using real-time PCR in plasma cells purified from 59 monoclonal gammopathy of undetermined significance (MGUS) and $140 \mathrm{MM}$ patients. The MM cell lines KMS11, KMS12PE, OPM2, and RPMI8226 were treated with JQ1, an MYC super-enhancer inhibitor, or MYC inhibitor 10058-F4. The expression levels of PVT1 and MYC were significantly higher in MM than in MGUS $(p<0.0001)$ and were positively correlated with disease progression $(r=0.394, p<0.0001)$. JQ1 inhibited cell proliferation and decreased the expression levels of MYC and PVT1. However, 10054-F4 did not alter the expression level of PVT1. The positive correlation between MYC and PVT1 in patients, the synchronous downregulation of MYC and PVT1 by JQ1, and the lack of effect of the MYC inhibitor on PVT1 expression suggest that the expression of these two genes is co-regulated by a super-enhancer. Cooperative effects between these two genes may contribute to MM pathogenesis and progression.
\end{abstract}

Keywords: long noncoding RNA; PVT1; MYC; bromodomain; multiple myeloma

\section{Introduction}

Multiple myeloma (MM) is a plasma cell neoplasm characterized by the proliferation of atypical plasma cells in the bone marrow and the production of monoclonal immunoglobulins. MM progresses from a precancerous state called monoclonal gammopathy of undetermined significance (MGUS) at a rate of approximately $1 \%$ per year [1-3]. The primary molecular mechanism of MM development is thought to be the activation of cancer-related genes by translocations of immunoglobulin heavy 
chain genes (IgH). The effects of these translocations include increased cyclin D1 expression by the translocation $\mathrm{t}(11 ; 14) \mathrm{IgH}-C C N D 1$, increased FGFR3/MMSET expression by $\mathrm{t}(4 ; 14) \operatorname{IgH}-F G F R 3 / M M S E T$, and increased $c-M A F$ expression by $\mathrm{t}(14 ; 16) \mathrm{IgH}-c-M A F$ [4]. These chromosomal abnormalities are observed at the MGUS stage, so additional abnormalities are required for progression to MM. Recent genomic and transcriptomic analyses have shown that oncogene mutations, such as RAS mutations, and aberrant overexpression of MYC play an important role in the progression of MM [5]. However, not all players have yet been elucidated.

Recent transcriptome-wide analyses have revealed a large number of noncoding RNAs that are transcribed but not translated and can influence a range of cellular processes, including cellular proliferation, apoptosis, and motility [6,7]. Among the noncoding RNAs, long noncoding RNAs (lncRNAs), transcripts $>200$ nucleotides in length, have emerged as a class of key regulatory RNAs [8]. LncRNAs are deregulated in many human cancers and are associated with disease progression [9-11]. Several studies, including ours, have shed light on the role of lncRNAs in MM progression [12-14].

Plasmacytoma Variant Translocation 1 (PVT1) is a lncRNA longer than 500 nucleotides, first found in mouse plasmacytoma [15] and then reported to be involved in the oncogenesis of many types of cancers [16,17]. PVT1 is located at the 8q24 locus adjacent to MYC [18], which is highly expressed in many types of cancer and plays an important role in carcinogenesis $[19,20]$. PVT1 is elevated in MM [5,21] and coamplified with MYC in many cancers [18]; there is an association between PVT1 expression level and poor prognosis in many cancers $[16,17,22-24]$. High-level amplification and/or overexpression of PVT1 is associated with an invasive phenotype of breast cancer and reduced survival time in ovarian cancer patients [25]. These observations indicate the involvement of PVT1 in the maintenance of a transformed phenotype. However, its regulation and clinical significance in MM are poorly documented.

Super-enhancers are areas of the genome at which mediator complexes, including activators and coactivators, accumulate at higher densities than on regular enhancers. Super-enhancers controlling the expression of genes involved in cell identity, determination, and disease were recently described [26]. The super-enhancers are bound by the bromodomain-containing protein 4 (BRD4), a member of the bromodomain protein family that is essential for RNA transcription and transcription elongation [27]. The most well-known mechanism of MYC overexpression is the fusion of the $\operatorname{IgH}$ enhancer and MYC produced by the chromosomal translocation $\mathrm{t}(8 ; 14)$ in Burkitt lymphoma. MYC transcription is controlled by a super-enhancer [27,28], and BRD4 inhibitors markedly decrease MYC expression in many types of cells, including MM cells [28]. It was speculated that PVT1 is regulated by a super-enhancer.

To clarify the mechanism of regulation of PVT1 expression and the relationship of PVT1 with progression and prognosis in MM, we investigated PVT1 expression in plasma and MM cell lines focusing on a super-enhancer-related mechanism, and the correlation between PVT1 and MYC expression in MM and MGUS patients.

\section{Results}

\subsection{PVT1 and MYC Expression in Plasma Cells of MM Is Higher than in MGUS or Control}

The expression levels of $P V T 1$ and $M Y C$ in plasma cells were significantly higher in MM (mean: PVT1 2.58, MYC 0.74) than in MGUS (mean: PVT1 0.88, MYC 0.06) and the control (mean: PVT1 0.06, MYC 0.07) $(p<0.001, p<0.001$, respectively; Figure 1A,B). PVT1 expression seemed to increase with disease progression, but it did not differ between samples from different stages (stages are defined according to the international staging system (ISS) reflecting progression) $(p=0.145$, Figure 1C). We then compared PVT1 expression levels between cell lines with different chromosomal abnormalities, as detected using interphase fluorescence in situ hybridization (iFISH) analysis, including $\mathrm{t}(11 ; 14)$, $\mathrm{t}(4 ; 14), \mathrm{t}(14 ; 16)$, deletion $13 \mathrm{q}$, and deletion $17 \mathrm{p}$, and found no differences $(p=0.509$, Figure 1D). Since PVT1 is located on chromosome 8q24 and co-occurrence of $8 \mathrm{q} 24$ abnormality is sometimes observed in MM, we compared the expression levels between cell lines with 8q24 abnormalities, including 
$\mathrm{t}(8 ; 14)$, and tested for 8q24 amplification using FISH analysis. However, no differences were found (Figure 1E). When we analyzed PVT1 and MYC expression levels in the same patients, a positive correlation was found in both MM and MGUS patients $(r=0.484, p<0.001 ; r=0.423, p<0.0001$; respectively; Figure 1E,F).

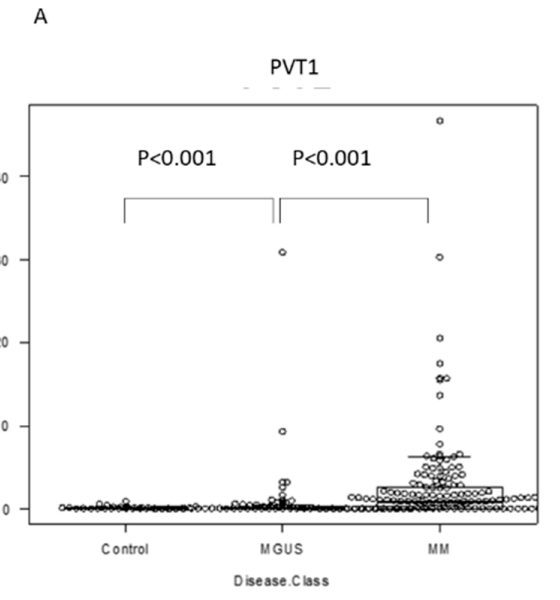

B
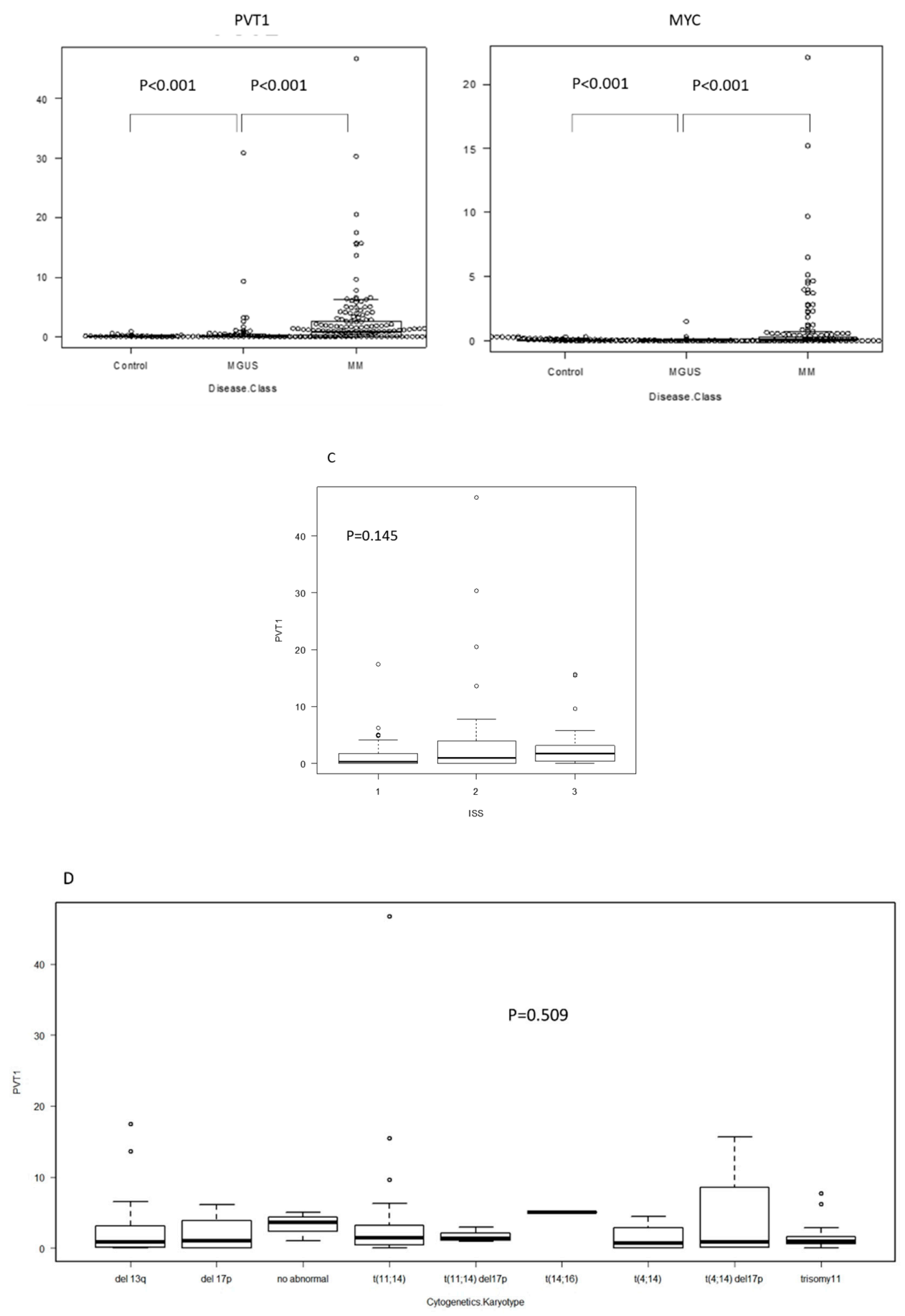

Figure 1. Cont. 


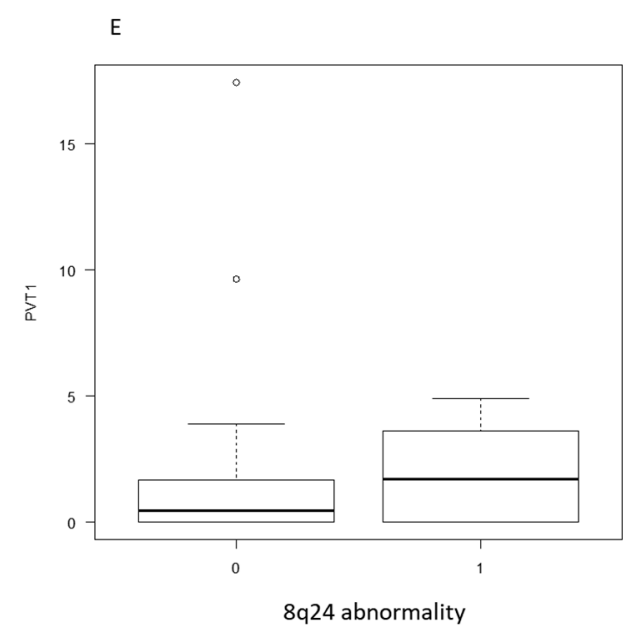

F
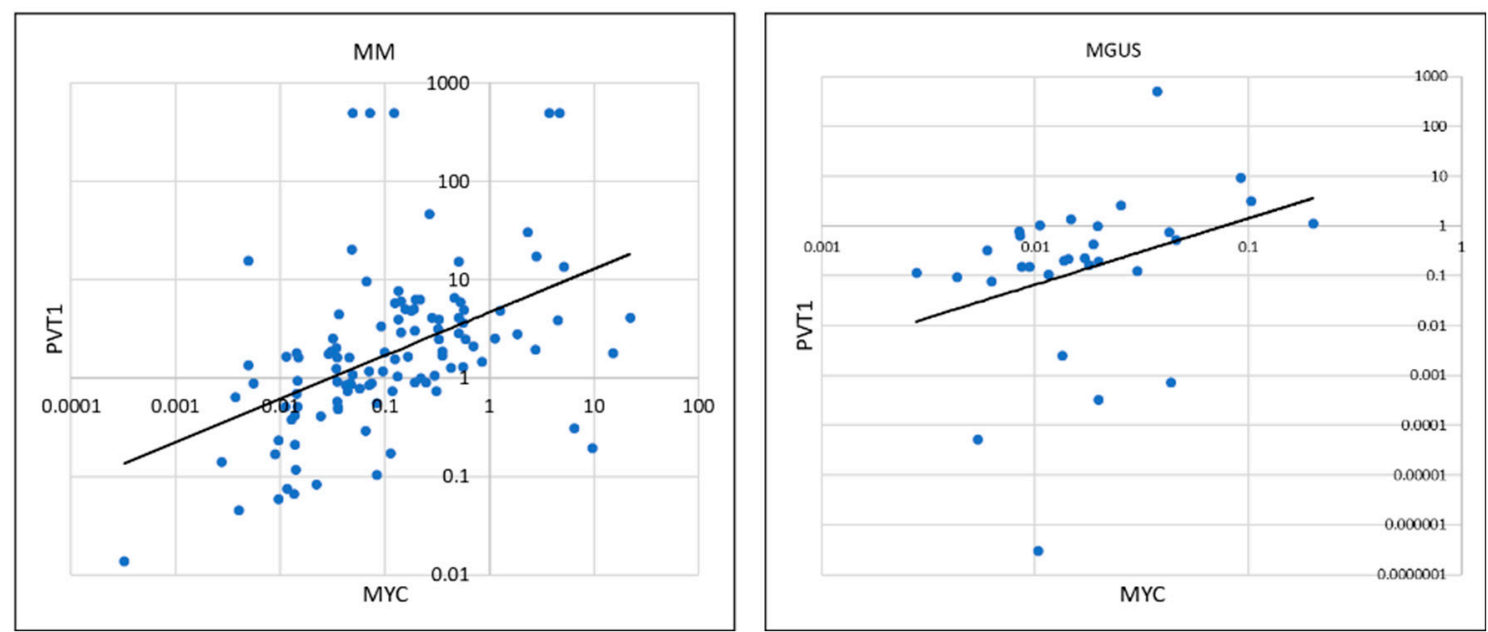

Figure 1. RNA expression determined using RQ-PCR in plasma cells isolated from bone marrow specimens, organized by patient status. Each dot represents a patient. RQ-PCR: real time quantitative PCR. MGUS: monoclonal gammopathy of undetermined significance. MM: multiple myeloma. (A) Plasmacytoma Variant Transcript 1 (PVT1), (B) MYC, and (C) PVT1 expression by international staging system (ISS). (D) PVT1 expression, according to karyotype, determined using fluorescence in situ hybridization (FISH). (E) PVT1 expression by chromosome 8q24 abnormality determined using FISH. (F) Correlation between PVT1 and MYC RNA expression in plasma cells of MM and MGUS.

\subsection{BRD4 Inhibitors Inhibit MM Cell Proliferation and Downregulate PVT1 and MYC Expression}

To clarify the mechanisms regulating PVT1 expression, we focused on BRD4 because MYC expression is regulated by BRD4. BRD4 inhibitors inhibited the proliferation of eight MM cell lines. JQ1 inhibited the proliferation of the cell lines KMS11, KMS12PE, KMS12BM, KMS26, KMM1, OPM2, and RPMI8226 at a concentration of $1 \mu \mathrm{M}$ (Figure 2A). CPI-203 inhibited the proliferation of KMS11, KMS12BM, KMS26, and OPM2 at a lower concentration $(0.1 \mu \mathrm{M})$, and inhibited KMS12PE, KMS18, KMM1, and RPMI8226 at $1 \mu \mathrm{M}$ concentration (Figure 2B). 

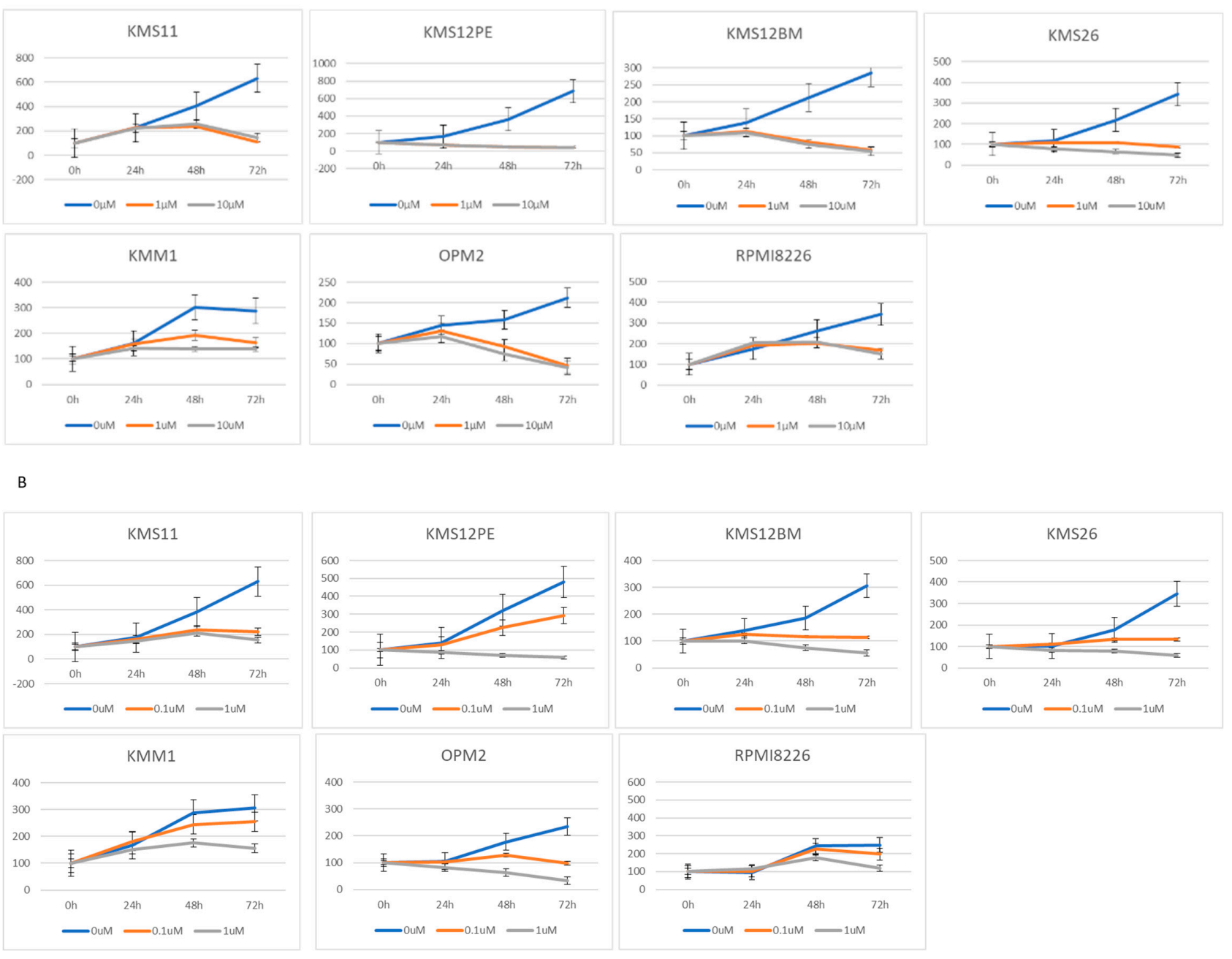

Figure 2. Cont. 
C

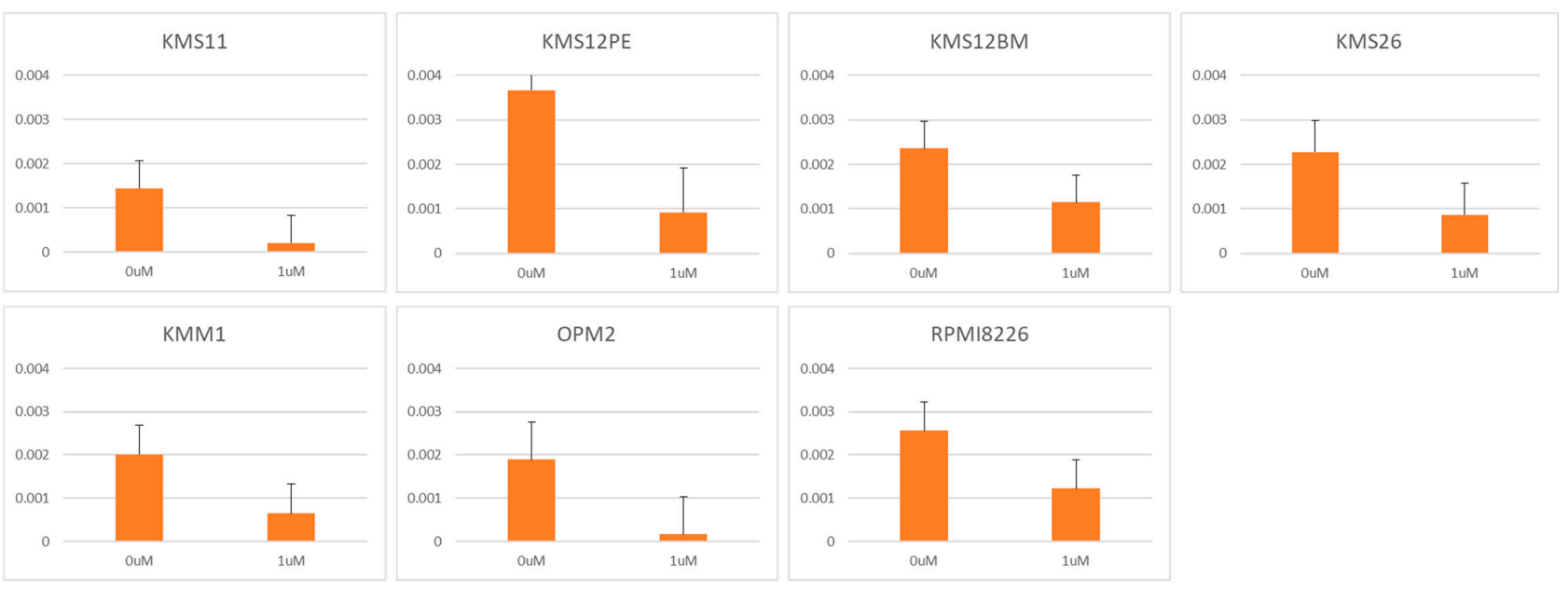

D

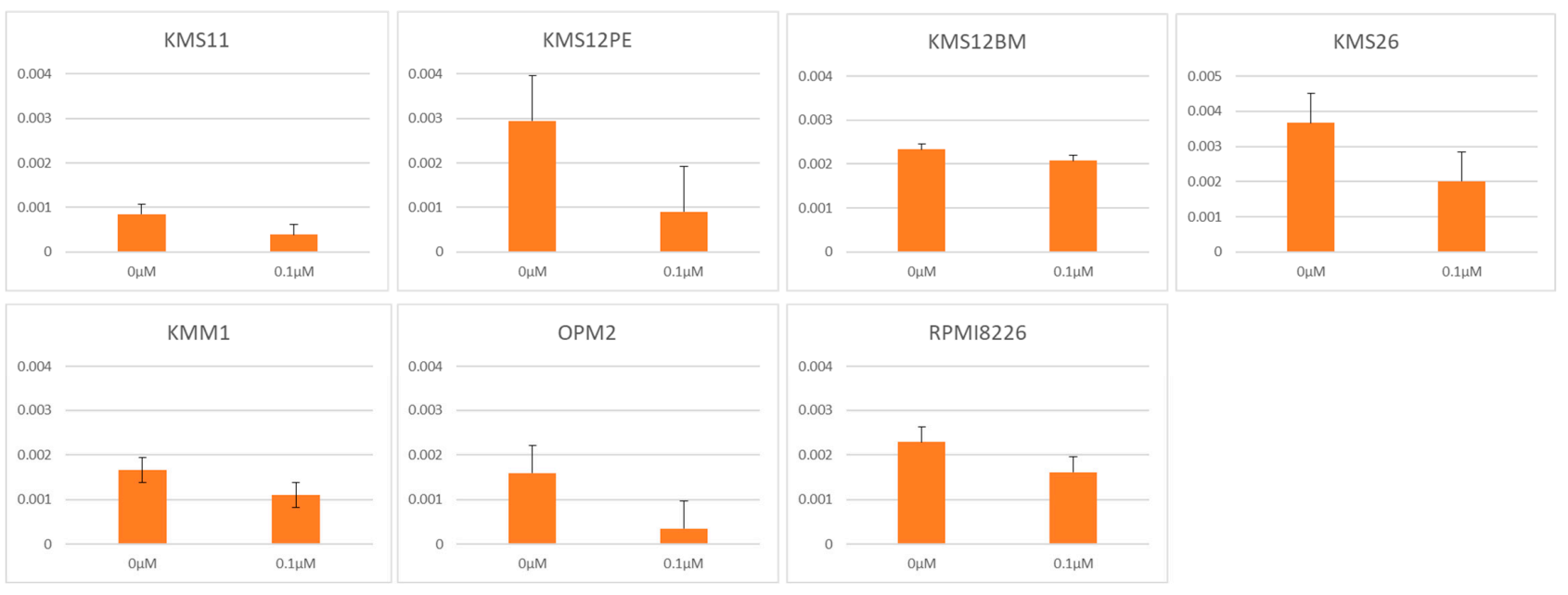

Figure 2. Cont. 
$\mathrm{E}$
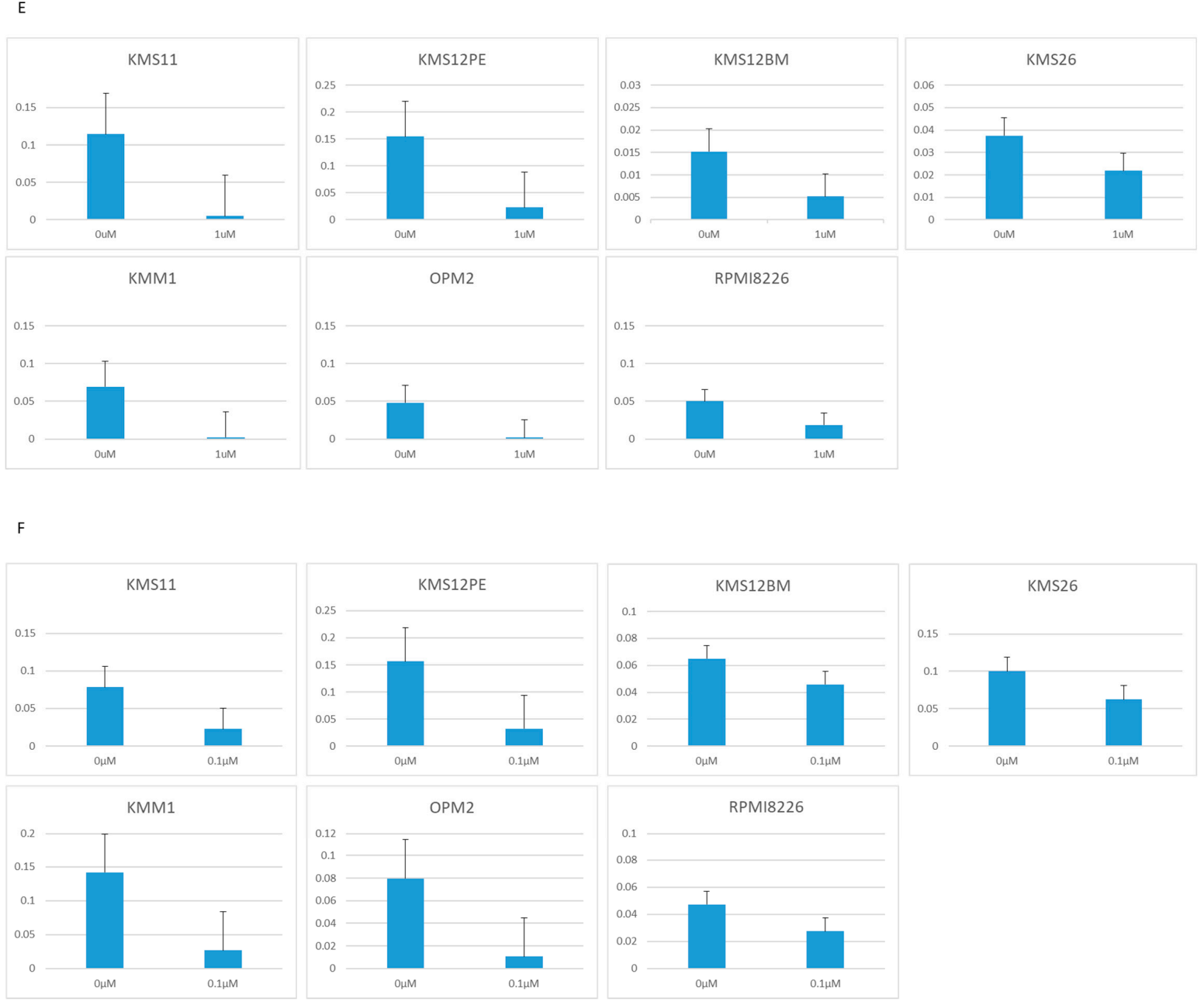

Figure 2. Growth determined using the WST-8 assay, and RNA expression determined using RQ-PCR in seven MM cell lines treated with two BRD4 inhibitors: JQ1 $(0,1,10 \mu \mathrm{M})$ and CPI-203 (0, 0.1, $1 \mu \mathrm{M})$. (A) Cell growth under treatment with JQ1. (B) Cell growth under treatment with CPI-203. (C) PVT1 expression under treatment with JQ1. (D) PVT1 expression under treatment with CPI-203. (E) MYC expression under treatment with JQ1. (F) MYC expression under treatment with CPI-203. 
JQ1 reduced the PVT1 mRNA expression at a concentration of $1 \mu \mathrm{M}$ in KMS11, OPM2, KMS12PE, KMS12BM, KMM1, RPMI8226, and KMS26 (Figure 2C). As with JQ1, another BRD4 inhibitor, CPI-203, reduced the PVT1 mRNA expression at a concentration of $1 \mu \mathrm{M}$, in KMS11, OPM2, KMS12PE, KMM1, RPMI8226, and KMS26 (Figure 2D).

Consistent with previous reports, $1 \mu \mathrm{M}$ of JQ1 and CPI-203 significantly reduced MYC mRNA expression in KMS11, OPM2, KMS12PE, KMS12BM, KMM1, RPMI8226, and KMS26 (Figure 2E,F).

\subsection{MYC Inhibitor Did Not Reduce PVT1 Expression}

From the results described above, there were two possible explanations for the high PVT1 expression levels in MM: MYC and PVT1 are co-regulated by BRD4 or PVT1 is regulated by MYC, which in turn is regulated by BRD4. To test these hypotheses, we used the MYC inhibitor 10058-F4, which inhibits MYC transcription activity by dissociating the MYC-MAX transcription complex. PVT1 expression was not significantly altered by treatment with 10058-F4 in KMS11, OPM2, KMS12PE, or RPMI8226 (Figure 3). Therefore, no contribution of MYC transcriptional activity to PVT1 expression was observed.

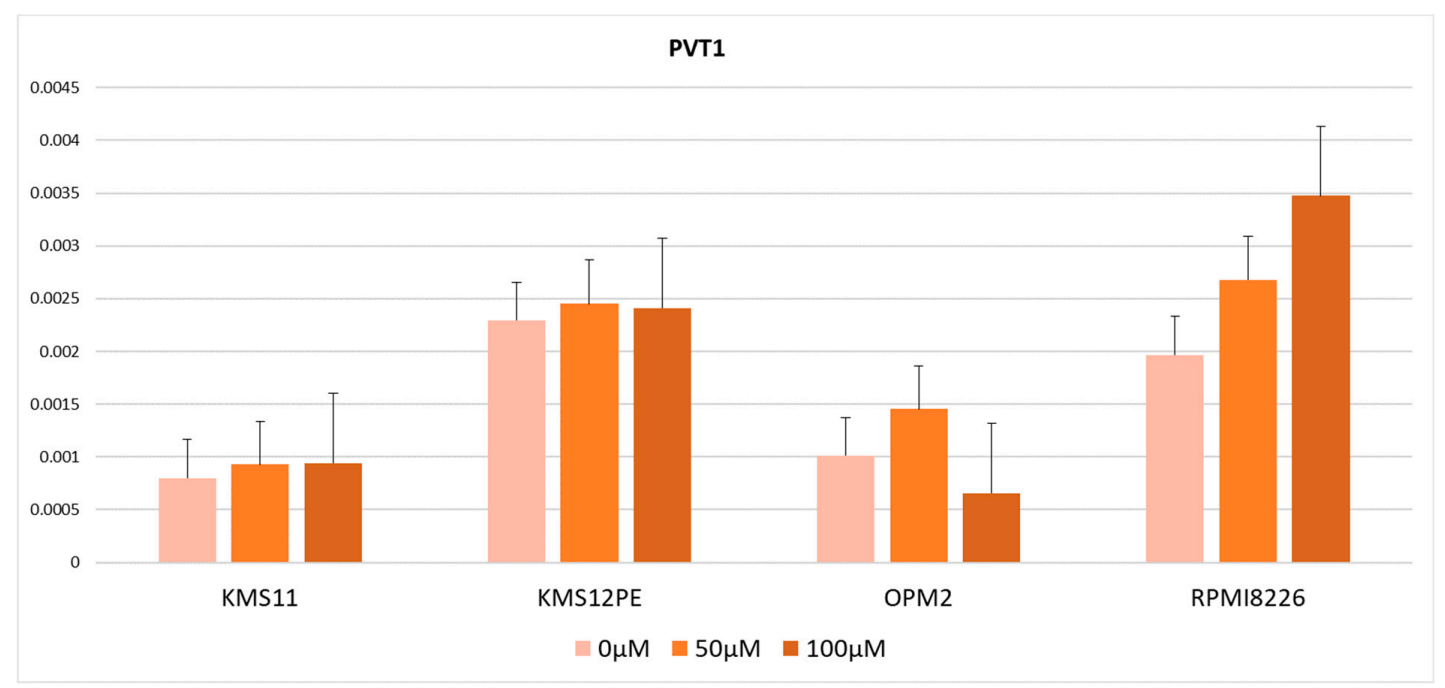

Figure 3. PVT1 expression in cells treated with the MYC inhibitor 10058-F4. Error bars show the standard error of mean (SEM).

\subsection{PVT1 Downregulation by Locked Anti-Sense Nucleotide Reduced MYC Expression}

To determine the role of PVT1 on MYC expression in MM cells, antisense locked nucleotide $\mathrm{GapmeR}^{\mathrm{TM}}$ was used to knockdown PVT1 expression. Three sequences of GapmeR were constructed and five MM cell lines were tested: KMS11, KMS12PE, KMM1, OPM2, and RPMI8226. PVT1 expression was successfully knocked down in two cell lines, KMS11 and OPM2, by one GapmeR product (Figure 4A). In these two cell lines, MYC mRNA expression was significantly reduced (Figure 4B). 
A

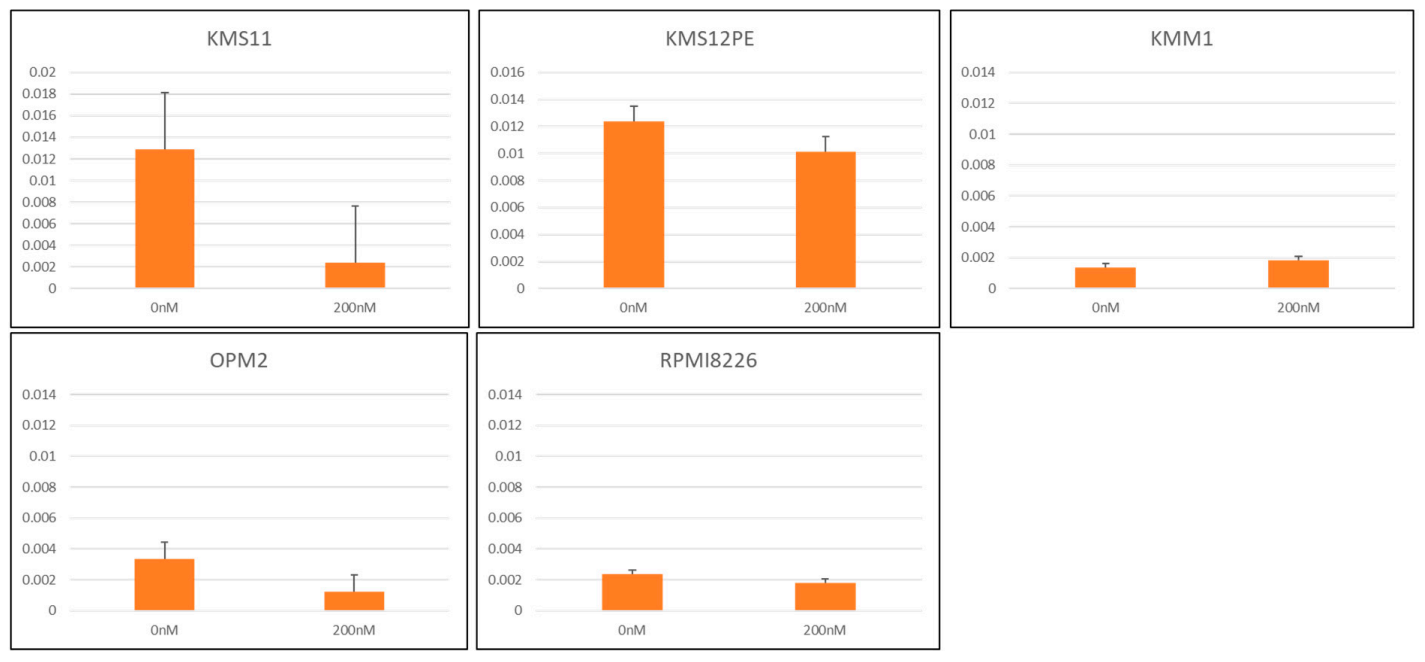

B

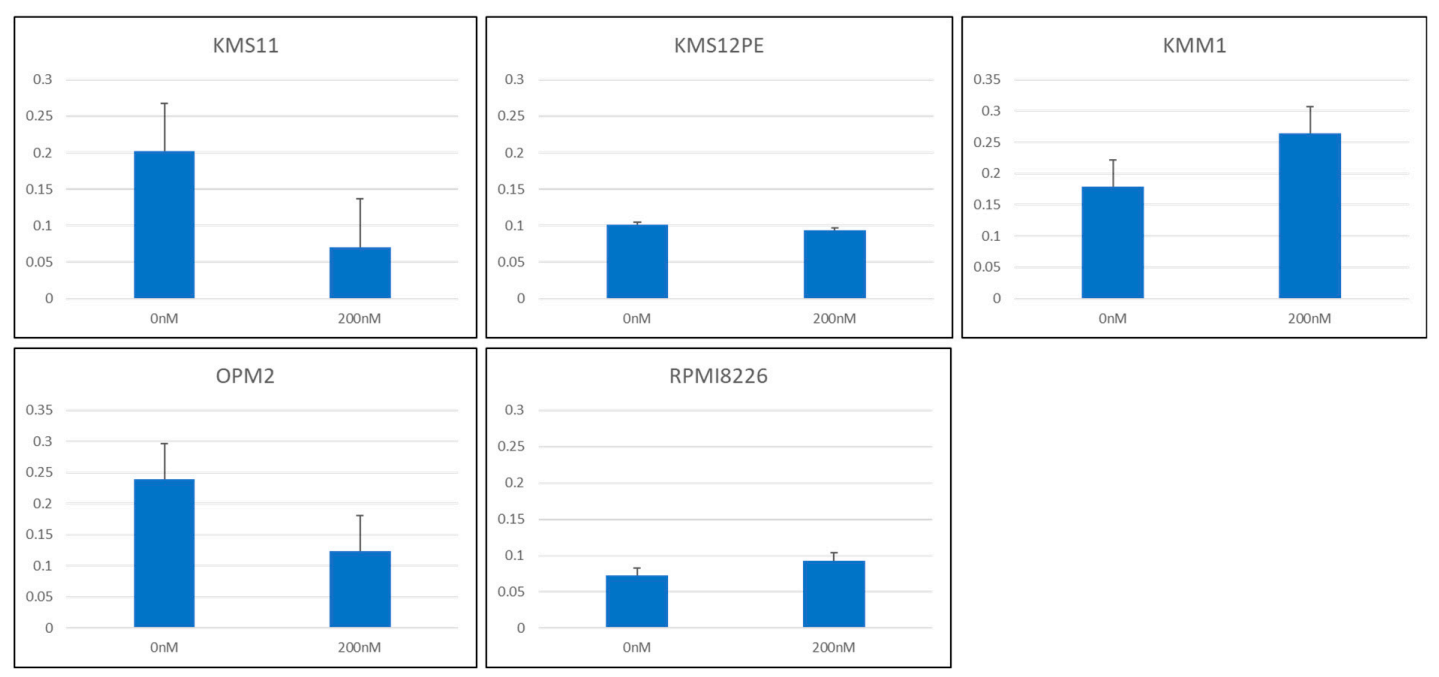

Figure 4. (A) PVT1 expression in MM cell lines treated with antisense oligonucleotide LNA ${ }^{\mathrm{TM}}$ long RNA GapmeR for PVT1. (B) MYC expression in MM cell lines treated with antisense nucleotide LNA ${ }^{\mathrm{TM}}$ long RNA GapmeR for PVT1.

\subsection{Clinical Significance of PVT1 Expression in MM}

To investigate the clinical significance of PVT1 in MM, the overall survival (OS) and progression-free survival (PFS) of MM patients were analyzed by dividing the two groups according to PVT1 expression levels using quartiles. Eighty-nine newly diagnosed multiple myeloma (NDMM) patients were analyzed for OS and 85 NDMM patients were analyzed for PFS. Seven patients were excluded from OS analysis and 11 patients were excluded from PFS analysis due to the lack of reliable clinical data. The patients with high PVT1 expression tended to have a shorter OS, with a median of 2.7 years compared to 5.0 years in those with low expression $(p=0.077$, Figure 5A). PFS also tended to be shorter in patients with high PVT1 expression, but the difference did not reach statistical significance $(p=0.095$, Figure 5B). 


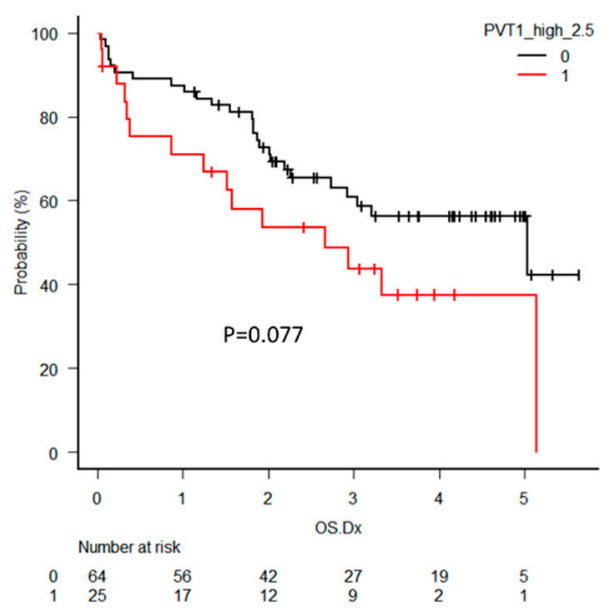

(A)

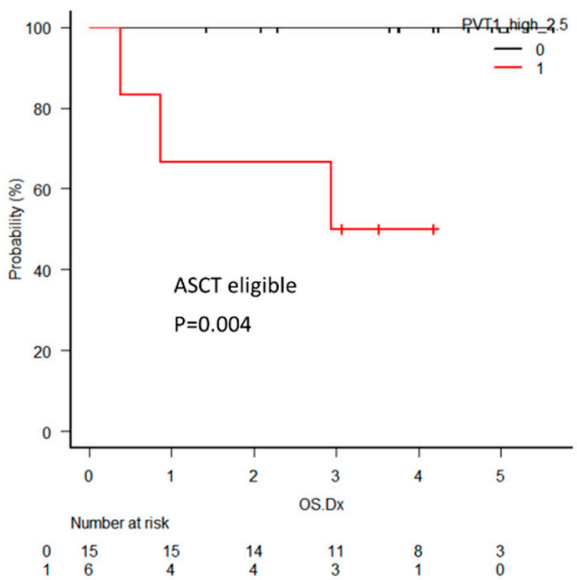

(C)

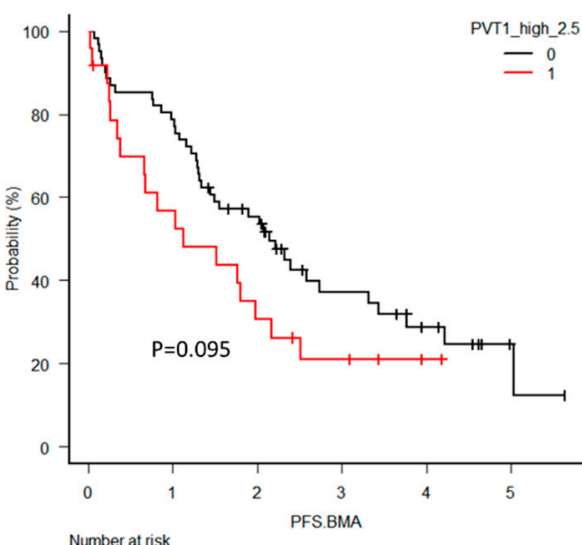

$\begin{array}{ccccccc}0 & 61 & 48 & 30 & 14 & 8 & 2 \\ 1 & 24 & 13 & 7 & 4 & 1 & 0\end{array}$

(B)

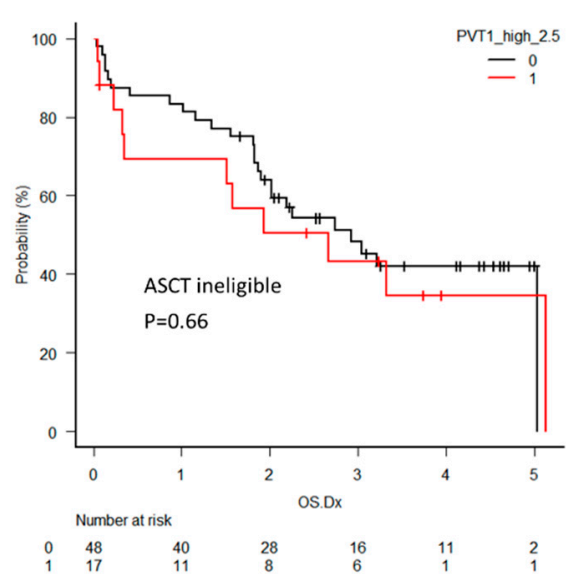

(D)

Figure 5. Cont. 


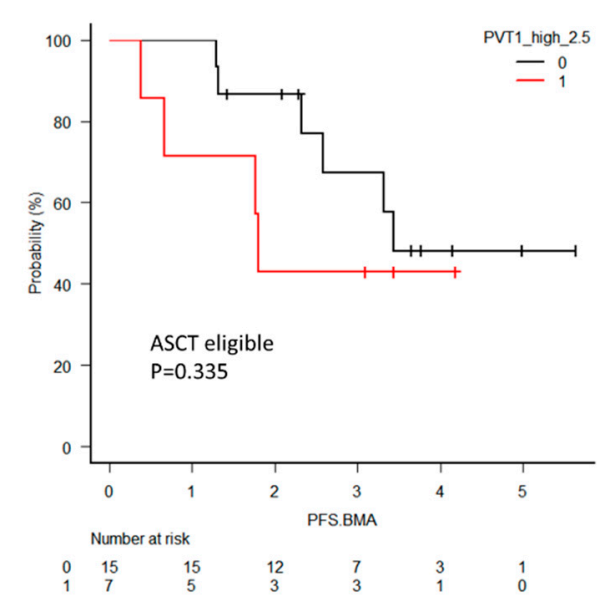

(E)

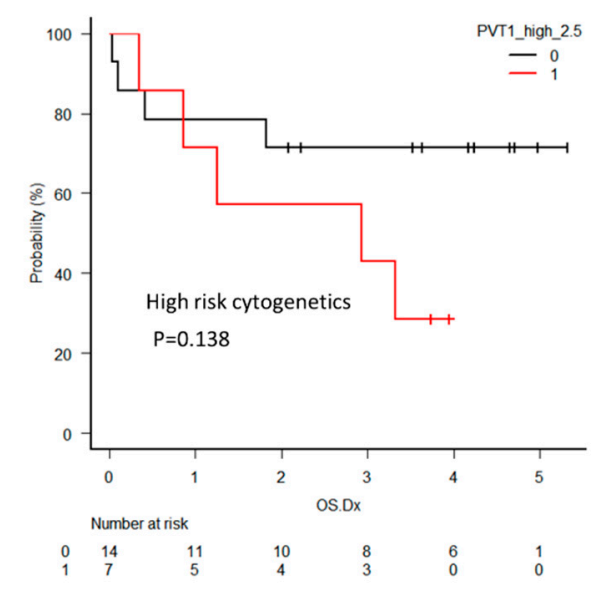

(G)

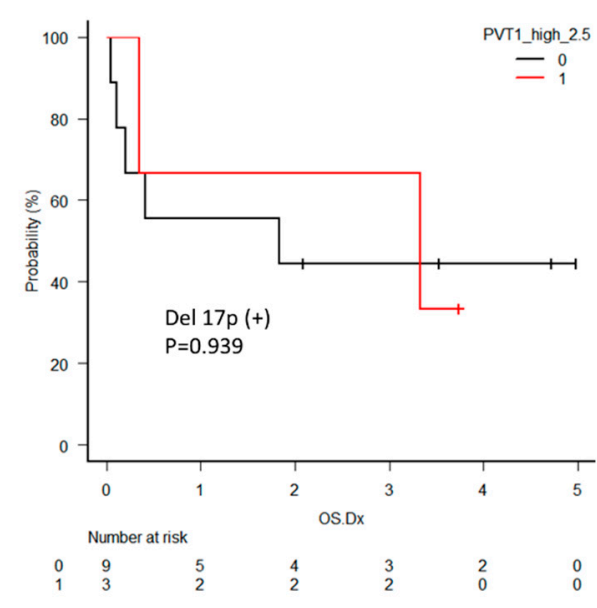

(I)

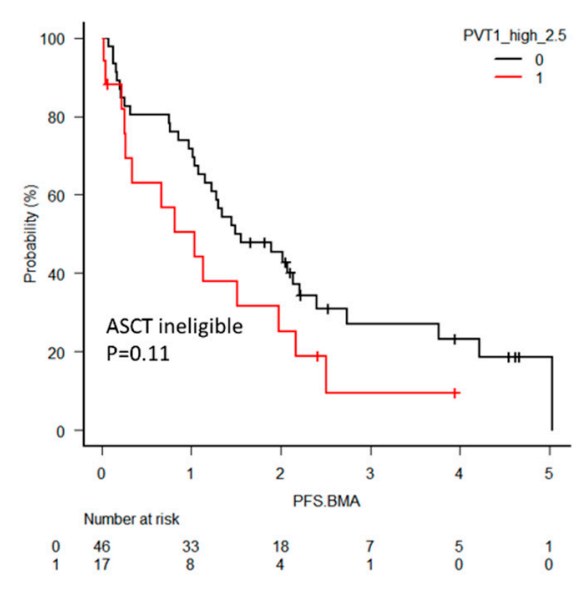

(F)

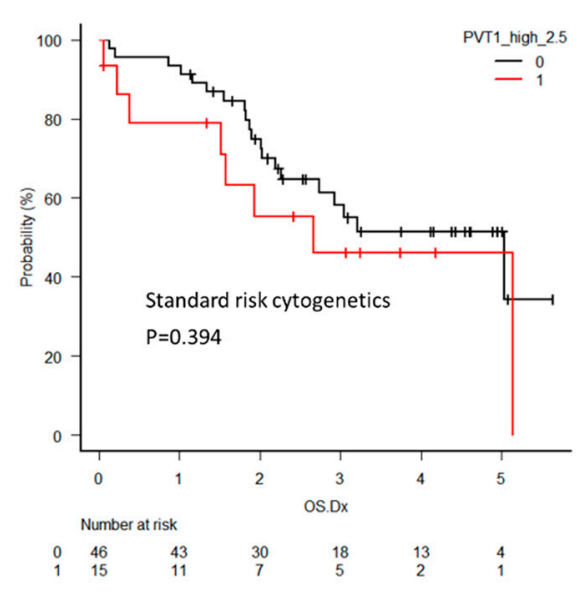

(H)

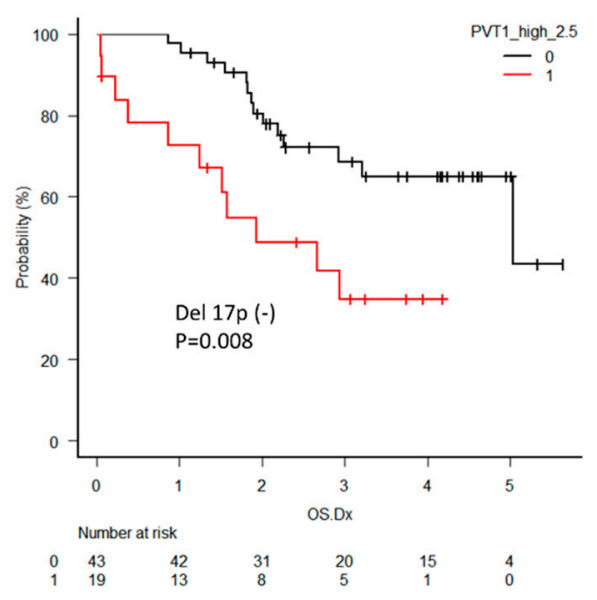

(J)

Figure 5. Cont. 


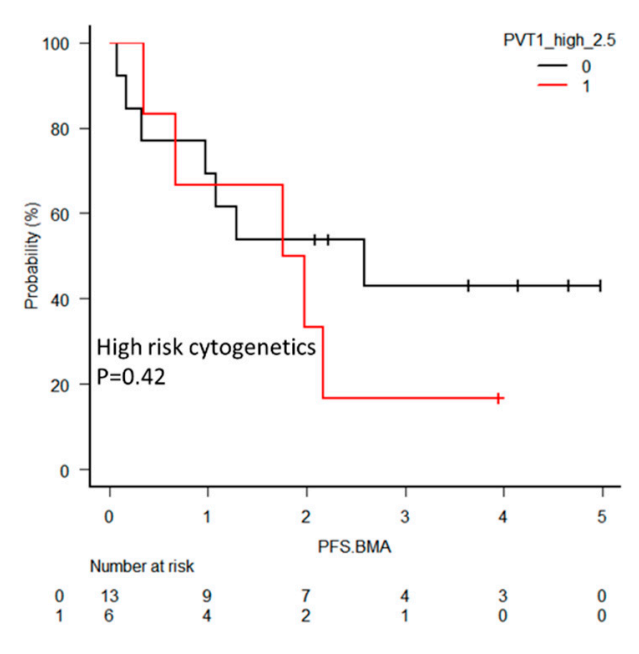

$(\mathbf{K})$

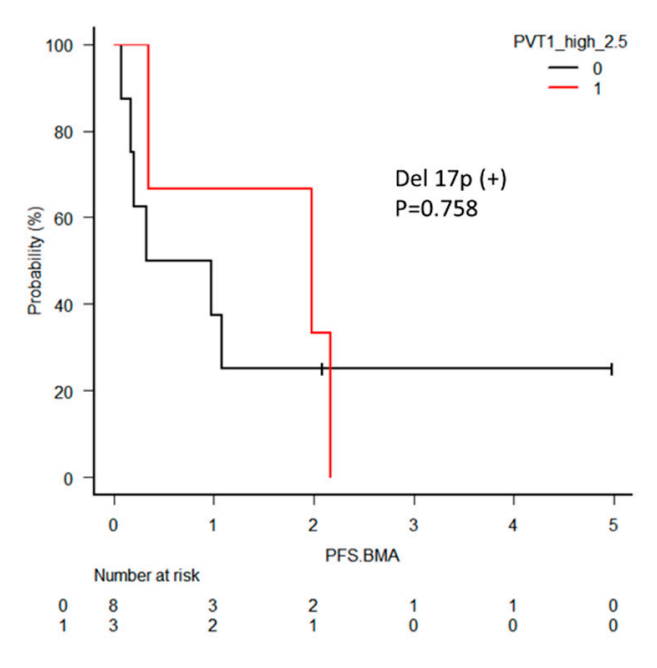

$(\mathbf{M})$

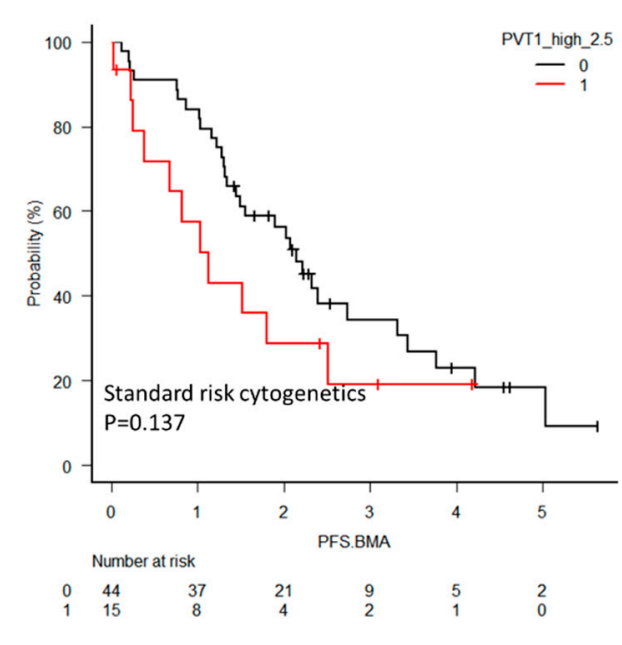

$(\mathbf{L})$

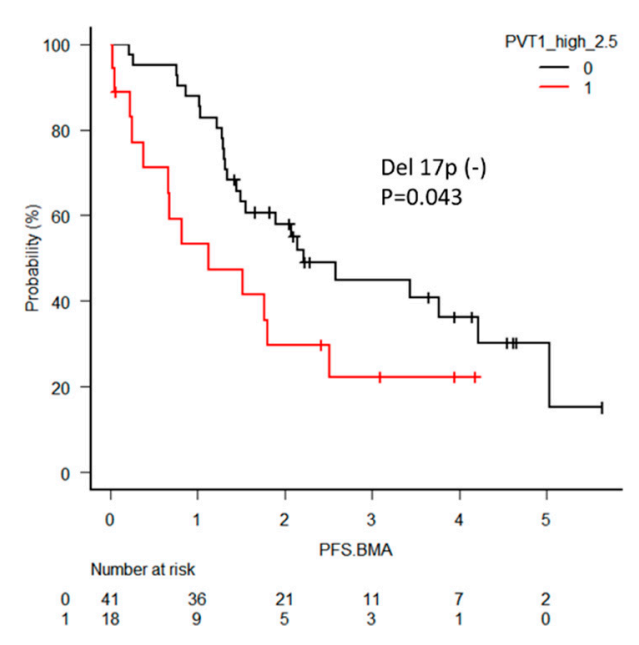

$(\mathbf{N})$

Figure 5. (A) Overall survival (OS) and (B) progression-free survival (PFS) in all newly diagnosed multiple myeloma (NDMM) patients divided into two groups by PVT1 expression level. (C) OS in NDMM patients eligible for autologous stem cell transplantation (ASCT). (D) OS in NDMM ineligible for ASCT. (E) PFS in NDMM eligible for ASCT. (F) PFS in NDMM ineligible for ASCT. (G) OS in NDMM with high-risk cytogenetics. (H) OS in NDMM with standard-risk cytogenetics. (I) OS in NDMM with deletion 17p (del 17p). (J) OS in NDMM without del 17p. (K) PFS in NDMM with high-risk cytogenetics. (L) PFS in NDMM with standard-risk cytogenetics. (M) PFS in NDMM with del 17p.

(N) PFS in NDMM without del 17p.

For further clarification of the clinical significance of PVT1 expression, OS and PFS were analyzed separatory by subcategories, including patients eligible or ineligible for autologous stem cell transplantation (ASCT), harboring high-risk or standard-risk cytogenetics, and harboring deletion 17p (del 17p). The ASCT eligible patients with high PVT1 expression showed significantly shorter OS $(p=0.004)$, but this significant difference was not found in the ASCT ineligible patients $(p=0.66)$. PFS in patients with high PVT1 expression in both groups was not different. OS and PFS between patients with high and low PVT1 expression did not differ in the groups of patients harboring high-risk and standard-risk cytogenetics. However, significantly shorter OS and PFS of the patients with high 
PVT1 expression was found in the groups of patients who did not harbor del 17p $(p=0.008, p=0.0043$, respectively), although this significant difference was not observed in the patients with del 17p.

\section{Discussion}

In this study, we aimed to clarify the mechanism of regulation of PVT1 expression and its relationship with progression and prognosis in MM. We found significantly higher PVT1 and MYC expressions in MM and MGUS plasma cells compared to the control cell line, suggesting that the lncRNA PVT1 is associated with MM pathogenesis and progression. A positive correlation between MYC and PVT1 expression levels suggested that MYC and PVT1 are co-regulated by the same mechanism. Two BRD4 inhibitors, JQ1 and CPI -203, reduced both MYC and PVT1 in MM cell lines, but the MYC inhibitor did not reduce PVT1 expression, suggesting that PVT1 expression is not controlled by MYC, but that both genes were regulated by BRD4. The reduction of MYC mRNA by PVT1 knockdown indicated that $P V T 1$ regulates $M Y C$ expression at the transcriptional level.

Our observation of the high expression of PVT1 and MYC in MM cells compared with normal plasma cells is consistent with those of previous studies [17]. Many studies have illustrated that PVT1 levels are higher in many cancers with an increased MYC expression than in normal tissues and are associated with a poor prognosis [16,23-25]. Tissue microarray analysis of primary tumors indicated a high correlation between $P V T 1$ and $M Y C$ expression, providing strong evidence for cooperation between PVT1 and MYC in different human cancers [29]. Nagoshi et al. reported that frequent PVT1 rearrangements and the novel chimeric genes PVT1-NBEA and PVT1-WWOX occur in MM with 8q24 abnormality [30]. They also found a high expression of PVT1 and MYC in most MM cell lines, regardless of $P V T 1$ or $M Y C$ rearrangement status. Our findings of $P V T 1$ elevation in plasma cells of MM compared to MGUS suggest a role of PVT1 in the pathogenesis of malignant clonal plasma cells and the progression from precancerous stages to cancer.

The precise mechanisms controlling the expression of the lncRNA PVT1 in MM have not been fully clarified. Increases in MYC copy number and PVT1 expression occur in more than $98 \%$ of cancer cases with increased 8q24 copy numbers, indicating an interaction between PVT1 and MYC and suggesting that they are part of a common signaling pathway. We could not find any correlation between PVT-1 expression level and chromosomal abnormalities, including $\mathrm{t}(8 ; 14)$ and 8q24 amplification detected using iFISH. This finding is not conclusive because iFISH is not sufficient for the detection of gene amplification; however, a positive correlation between PVT1 and MYC expression implies a common system of regulation for both genes and indicates that upregulation of PVT1 and MYC expression does not solely depend on 8q24 abnormalities in MM.

We speculated that a BRD4 inhibitor would downregulate the expression of PVT1 and MYC. JQ1 and CPI -203 significantly reduced the expression of PVT1 in myeloma cell lines. Combined with the high expression of MYC and PVT1, and the positive correlation between MYC and PVT1 in the MM and MGUS patients' plasma cells, these results suggest that MYC and PVT1 are regulated by the same mechanism. There were two possible regulation mechanisms for $M Y C$ and PVT1 expression. One is that MYC regulates PVT1 expression and the other is that both MYC and PVT1 are controlled by the super-enhancer. To test these hypotheses, we examined PVT1 expression using 10058-F4, which suppresses the transcriptional activity of MYC by inhibiting the formation of an MYC and MAX heterodimer [31]. The administration of 10058-F4 did not decrease PVT1 expression, except in the OPM2 cell line. These results suggest that PVT1 is not transcriptionally regulated by MYC and that the two genes are simultaneously regulated by super-enhancers. This result is inconsistent with previous reports that the PVT1 promoter region contains two enhancer E-boxes that serve as MYC binding sites and that E-box 2 mediates the binding of MYC to the PVT1 promoter to promote PVT1 expression [32]. We cannot fully explain this discrepancy. It may be caused by differences in the cell lineages or by differences in the conditions of the cells.

Many studies have revealed a relationship between PVT1 and MYC expression. Our experiments with PVT1 knockdown using the locked nucleotide antisense oligonucleotide resulted in decreased 
expression of MYC mRNA, a consistent observation with a previous report depicting the effect of PVT1 on MYC transcription [33], but inconsistent with another report in which low levels of c-Myc protein were found without significant changes in MYC mRNA levels when siRNA was used to knock down PVT1 [29].

We found a tendency toward shorter OS and PFS in the high PVT1 group, although these differences did not reach statistical significance. These results suggested that a high level of PVT1 might be associated with a prognosis of relapse and drug resistance. An association between high PVT1 expression and poor prognosis was reported in several cancers $[16,23,25]$. The involvement of PVT1 in resistance to anticancer drugs through several pathways was documented [24,34]. For example, PVT1 acts as a competitive endogenous RNA that forms a tight network with protein-coding mRNAs, such as CDH1, TP73, TP31, RUNX1, and RUNX via microRNA-200, thereby regulating breast cancer progression $[35,36]$. For further clarification, we performed a subgroup analysis. The prognostic significance of high PVT1 was apparent when the survival data excluding the patients with del 17p were analyzed. Del 17p is one of the worst prognostic factors; therefore, it strongly impacts survival and may mask the effects of PVT1. Research into treatment targeting PVT1, such as the use of BRD4 inhibitors, may be warranted only for some specific subcategories of patients. We acknowledge the argument that this type of subgroup analysis in a small number of patients cannot be used to draw definitive conclusions. However, our results provide some basis for further studies aimed at elucidating PVT1 involvement in MM progression and drug resistance.

\section{Materials and Methods}

\subsection{Cell Lines}

The cell lines used are listed in Table S1, with cytogenetic information. The human myeloma cell line RPMI8226 was obtained from the American Type Culture Collection (Rockville, MD, USA), and lines KMS11, KMS12PE, KMS12BM, KMM1, and KMS26 were kindly provided by Takemi Otsuki (Kawasaki Medical School, Okayama, Japan). OPM2 was kindly provided by Masaki Ri (Nagaya City University, Nagoya, Japan). All lines were cultured in RPMI 1640 medium (Sigma-Aldrich, St. Louis, MO, USA), supplemented with $10 \%$ fetal bovine serum at $37^{\circ} \mathrm{C}$ and $5 \% \mathrm{CO}_{2}$.

\subsection{Patients}

In this study, we included a total of $137 \mathrm{MM}$ patients (including 96 newly diagnosed MM (NDMM), 26 relapse refractory MM (RRMM), and 15 smoldering MM (SMM)), 62 with MGUS, and 21 control patients with lymphoma without bone marrow infiltration or acute myeloid leukemia in complete remission. Patients were recruited from July 2010 to March 2016. The patient characteristics are summarized in Table S2. This study was approved by Gunma University Hospital Clinical Research Review Board under the guidelines of the Declaration of Helsinki (project code 1295, approved data 22-Apr-2020). Bone marrow (BM) aspirate samples were obtained upon diagnosis after obtaining each patient's informed consent.

\subsection{Treatment with Inhibitors}

Myeloma cell lines KMS11, KMS12PE, KMS12BM, KMS26, KMM1, OPM2, and RPMI8226 were treated with $1 \mu \mathrm{M}$ JQ1 and $0.1 \mu \mathrm{M}$ CPI203. The cell lines KMS11, KMS12PE, KMM1, OPM2, and RPMI8226 were treated for $24 \mathrm{~h}$ with an MYC inhibitor 10058-F4 (50 or $100 \mu \mathrm{M})$. Cell growth was determined using the WST-8 assay (Dojindo Laboratory, Kumamoto, Japan) at 24, 48, and $72 \mathrm{~h}$. RNA was isolated from cells incubated for $24 \mathrm{~h}$, and gene expression was determined using real-time PCR. The experiments were performed in triplicate. 


\subsection{PVT1 Silencing in Myeloma Cell Lines}

RNase H-activating locked nucleic acid (LNA) GapmeR ${ }^{\text {TM }}$ (Exiqon, Vedbaek, Denmark) was used to silence PVT1 expression in vitro. The cell lines KMS12PE and OPM2 were cultured with GapmeR for 24,48 , and $72 \mathrm{~h}$, after which cell viability was determined using the WST- 8 assay. All experiments were performed in duplicate. Gene expression was determined after $72 \mathrm{~h}$ of treatment.

\subsection{Isolation of Nucleic Acids}

Plasma cells were purified from bone marrow mononuclear cells with anti-CD138 antibody conjugated with phycoerythrin (PE) (Beckman Coulter, Brea, CA, USA) and the Easy Step PE positive selection kits containing anti-PE antibodies conjugated with micro-magnetic beads (STEMCELL Technologies, Vancouver, BC, Canada). RNA was extracted from the plasma cells (and one autopsied extramedullary plasmacytoma of the liver) and cell lines using mirVana RNA Isolation kits (Ambion, Austin, TX, USA). Complimentary DNA (cDNA) was produced using PrimeScript ${ }^{\mathrm{TM}} \mathrm{RT}$ reagent kits with gDNA Eraser (TaKaRa Bio, Kyoto, Japan).

\subsection{Real-Time PCR Analysis of PVT1 Expression}

The transcript levels, including those of PVT1, were determined using real-time PCR with the Power SYBR Green PCR Master Mix (Applied Biosystems, Foster City, CA, USA). Primers used for detection were as follows: PVT1: F-5'-CACTCTGGACGACTTGAGAAC-3', R- 5'-TCCTCAGATGAACCAGGTGAACA-3'; MYC: F-5'-CCTGGTGCTCCATGAGGAGA-3', R-5'-CAGTGGGCTGTGAGGAGGGTTT-3'; ACTB: F- 5' ${ }^{\prime}$-TGGCACCCAGCAATGAA-3', R- 5'-CTAAGTCATAGTCCGCCTAGAAGCA-3'. The expression levels were calculated using the $\triangle \triangle \mathrm{Ct}$ method. ACTB was used as an internal control, and cDNA extracted from the HL60 acute myeloid leukemia cell line was used as a calibration sample. The relative RNA expression levels are expressed as $2^{-\Delta \Delta C t}$.

\subsection{Statistical Analysis}

EZR version 1.41 (Saitama, Japan) was used for the statistical analysis. $p$ values $<0.05$ were considered significant. The frequencies were evaluated using Fisher's exact tests, and the continuous values were evaluated using Mann-Whitney U tests or Kruskal-Wallis tests. The overall survival (OS) and the progression-free survival (PFS) were evaluated using the Kaplan-Meier method and log-rank test for univariate analysis. The Cox regression hazard model was used for multivariate analysis.

\section{Conclusions}

We observed a positive correlation between MYC and PVT1 in patients, synchronous downregulation of MYC and PVT1 by JQ1 and CPI203, and no effect of MYC inhibitor for PVT1 expression, suggesting that the expression of these two genes is co-regulated by the BRD4 complex. PVT1 and MYC cooperation may contribute to MM pathogenesis and progression. Our results support the rationale for targeting $B R D 4$ in these patients.

Supplementary Materials: The following are available online at http://www.mdpi.com/1422-0067/21/19/7121/s1, Table S1: Cell lines characteristics, Table S2: Patients characteristics.

Author Contributions: H.H. and K.H. contributed equally to this work. Conceptualization, Writing-Original Draft Preparation, Writing-Review \& Editing, Investigation, Analysis, Validation, Project Administration. Funding Acquisition, Supervision, H.H.; Writing_-Original Draft Preparation, Methodology, and Investigation, K.H.; Investigation, Methodology, Analysis, and Validation, T.O., N.K., Y.K., K.K.-M., S.W., R.I., Y.M. (Yuki Murakami), Y.M. (Yuta Masuda), K.-i.T., H.T., and T.K.; Supervision, T.S., and H.M. All authors have read and agreed to the published version of the manuscript.

Funding: Supported by Grants-in-Aid from the Ministry of Education, Science and Culture, Japan. Grant number 26460665.

Conflicts of Interest: The authors declare no conflict of interest. 


\section{References}

1. Kyle, R.A.; Rajkumar, S.V. Multiple Myeloma. Blood 2008, 111, 2962-2972. [CrossRef] [PubMed]

2. Palumbo, A.; Anderson, K. Multiple Myeloma. N. Engl. J. Med. 2011, 364, 1046-1060. [CrossRef] [PubMed]

3. Kyle, R.A.; Larson, D.R.; Therneau, T.M.; Dispenzieri, A.; Kumar, S.; Cerhan, J.R.; Rajkumar, S.V. Long-Term Follow-Up of Monoclonal Gammopathy of Undetermined Significance. N. Engl. J. Med. 2018, 378, 241-249. [CrossRef] [PubMed]

4. Chesi, M.; Bergsagel, P.L. Molecular Pathogenesis of Multiple Myeloma: Basic and Clinical Updates. Int. J. Hematol. 2013, 97, 313-323. [CrossRef]

5. Bakkus, M.H.; Brakel-van Peer, K.M.; Michiels, J.J.; van't Veer, M.B.; Benner, R. Amplification of the c-myc and the pvt-Like Region in Human Multiple Myeloma. Oncogene 1990, 5, 1359-1364.

6. Iyer, M.K.; Niknafs, Y.S.; Malik, R.; Singhal, U.; Sahu, A.; Hosono, Y.; Barrette, T.R.; Prensner, J.R.; Evans, J.R.; Zhao, S.; et al. The Landscape of Long Noncoding RNAs in the Human Transcriptome. Nat. Genet. 2015, 47, 199-208. [CrossRef] [PubMed]

7. Djebali, S.; Davis, C.A.; Merkel, A.; Dobin, A.; Lassmann, T.; Mortazavi, A.; Tanzer, A.; Lagarde, J.; Lin, W.; Schlesinger, F.; et al. Landscape of Transcription in Human Cells. Nature 2012, 489, 101-108. [CrossRef]

8. Johnsson, P.; Morris, K.V. Expanding the Functional Role of Long Noncoding RNAs. Cell Res. 2014, 24, 1284-1285. [CrossRef]

9. Zhang, R.; Xia, L.Q.; Lu, W.W.; Zhang, J.; Zhu, J.S. LncRNAs and Cancer. Oncol. Lett. 2016, 12, $1233-1239$. [CrossRef]

10. Yarmishyn, A.A.; Kurochkin, I.V. Long Noncoding RNAs: A Potential Novel Class of Cancer Biomarkers. Front. Genet. 2015, 6, 145. [CrossRef]

11. Schmitt, A.M.; Chang, H.Y.L. Long Noncoding RNAs in Cancer Pathways. Cancer Cell 2016, $29,452-463$. [CrossRef] [PubMed]

12. Handa, H.; Kuroda, Y.; Kimura, K.; Masuda, Y.; Hattori, H.; Alkebsi, L.; Matsumoto, M.; Kasamatsu, T.; Kobayashi, N.; Tahara, K.I.; et al. Long Non-Coding RNA MALAT1 Is an Inducible Stress Response Gene Associated with Extramedullary Spread and Poor Prognosis of Multiple Myeloma. Br. J. Haematol. 2017, 179, 449-460. [CrossRef]

13. Cui, Y.S.; Song, Y.P.; Fang, B.J. The Role of Long Non-Coding RNAs in Multiple Myeloma. Eur. J. Haematol. 2019, 103, 3-9. [CrossRef] [PubMed]

14. Butova, R.; Vychytilova-Faltejskova, P.; Souckova, A.; Sevcikova, S.; Hajek, R.L. Long Non-Coding RNAs in Multiple Myeloma. Noncoding RNA 2019, 5, 13. [CrossRef]

15. Cory, S.; Graham, M.; Webb, E.; Corcoran, L.; Adams, J.M. Variant (6;15) Translocations in Murine Plasmacytomas Involve a chromosome 15 Locus at Least $72 \mathrm{~Kb}$ From the c-myc Oncogene. EMBO J. 1985, 4, 675-681. [CrossRef] [PubMed]

16. Lu, D.; Luo, P.; Wang, Q.; Ye, Y.; Wang, B. lncRNA PVT1 in Cancer: A Review and Meta-Analysis. Clin. Chim. Acta 2017, 474, 1-7. [CrossRef]

17. Colombo, T.; Farina, L.; Macino, G.; Paci, P. PVT1: A Rising Star Among Oncogenic Long Noncoding RNAs. BioMed Res. Int. 2015, 2015, 304208. [CrossRef]

18. Shtivelman, E.; Bishop, J.M. The PVT Gene Frequently Amplifies with MYC in Tumor Cells. Mol. Cell. Biol. 1989, 9, 1148-1154. [CrossRef]

19. Felsher, D.W.; Bishop, J.M. Reversible Tumorigenesis by MYC in Hematopoietic Lineages. Mol. Cell 1999, 4, 199-207. [CrossRef]

20. Lin, C.Y.; Lovén, J.; Rahl, P.B.; Paranal, R.M.; Burge, C.B.; Bradner, J.E.; Lee, T.I.; Young, R.A. Transcriptional Amplification in Tumor Cells With Elevated c-Myc. Cell 2012, 151, 56-67. [CrossRef]

21. Yang, M.; Zhang, L.; Wang, X.; Zhou, Y.; Wu, S. Down-Regulation of miR-203a by lncRNA PVT1 in Multiple Myeloma Promotes Cell Proliferation. Arch. Med. Sci. 2018, 14, 1333-1339. [CrossRef]

22. Xiao, M.; Feng, Y.; Liu, C.; Zhang, Z. Prognostic Values of Long Noncoding RNA PVT1 in Various Carcinomas: An Updated Systematic Review and Meta-Analysis. Cell Prolif. 2018, 51, e12519. [CrossRef]

23. Onagoruwa, O.T.; Pal, G.; Ochu, C.; Ogunwobi, O.O. Oncogenic Role of PVT1 and Therapeutic Implications. Front. Oncol. 2020, 10, 17. [CrossRef] [PubMed] 
24. Liu, C.; Jin, J.; Liang, D.; Gao, Z.; Zhang, Y.; Guo, T.; He, Y.L. Long Noncoding RNA PVT1 as a Novel Predictor of Metastasis, Clinicopathological Characteristics and Prognosis in Human Cancers: A Meta-Analysis. Pathol. Oncol. Res. 2019, 25, 837-847. [CrossRef] [PubMed]

25. Guan, Y.; Kuo, W.L.; Stilwell, J.L.; Takano, H.; Lapuk, A.V.; Fridlyand, J.; Mao, J.H.; Yu, M.; Miller, M.A.; Santos, J.L.; et al. Amplification of PVT1 Contributes to the Pathophysiology of Ovarian and Breast Cancer. Clin. Cancer Res. 2007, 13, 5745-5755. [CrossRef] [PubMed]

26. Hnisz, D.; Abraham, B.J.; Lee, T.I.; Lau, A.; Saint-André, V.; Sigova, A.A.; Hoke, H.A.; Young, R.A. Super-Enhancers in the Control of Cell Identity and Disease. Cell 2013, 155, 934-947. [CrossRef]

27. Lovén, J.; Hoke, H.A.; Lin, C.Y.; Lau, A.; Orlando, D.A.; Vakoc, C.R.; Bradner, J.E.; Lee, T.I.; Young, R.A. Selective Inhibition of Tumor Oncogenes by Disruption of Super-Enhancers. Cell 2013, 153, 320-334. [CrossRef]

28. Delmore, J.E.; Issa, G.C.; Lemieux, M.E.; Rahl, P.B.; Shi, J.; Jacobs, H.M.; Kastritis, E.; Gilpatrick, T.; Paranal, R.M.; Qi, J.; et al. BET Bromodomain Inhibition as a Therapeutic Strategy to Target c-Myc. Cell 2011, 146, 904-917. [CrossRef]

29. Tseng, Y.Y.; Moriarity, B.S.; Gong, W.; Akiyama, R.; Tiwari, A.; Kawakami, H.; Ronning, P.; Reuland, B.; Guenther, K.; Beadnell, T.C.; et al. PVT1 Dependence in Cancer With MYC Copy-Number Increase. Nature 2014, 512, 82-86. [CrossRef]

30. Nagoshi, H.; Taki, T.; Hanamura, I.; Nitta, M.; Otsuki, T.; Nishida, K.; Okuda, K.; Sakamoto, N.; Kobayashi, S.; Yamamoto-Sugitani, M.; et al. Frequent PVT1 Rearrangement and Novel Chimeric Genes PVT1-NBEA and PVT1-WWOX Occur in Multiple Myeloma With 8q24 Abnormality. Cancer Res. 2012, 72, 4954-4962. [CrossRef]

31. Yin, X.; Giap, C.; Lazo, J.S.; Prochownik, E.V. Low Molecular Weight Inhibitors of Myc-Max Interaction and Function. Oncogene 2003, 22, 6151-6159. [CrossRef]

32. Carramusa, L.; Contino, F.; Ferro, A.; Minafra, L.; Perconti, G.; Giallongo, A.; Feo, S. The PVT-1 Oncogene Is a Myc Protein Target That Is Overexpressed in Transformed Cells. J. Cell. Physiol. 2007, 213, 511-518. [CrossRef] [PubMed]

33. Houshmand, M.; Yazdi, N.; Kazemi, A.; Atashi, A.; Hamidieh, A.A.; Anjam Najemdini, A.; Mohammadi Pour, M.; Nikougoftar Zarif, M.L. Long Non-Coding RNA PVT1 as a Novel Candidate for Targeted Therapy in Hematologic Malignancies. Int. J. Biochem. Cell Biol. 2018, 98, 54-64. [CrossRef] [PubMed]

34. Li, M.Y.; Tang, X.H.; Fu, Y.; Wang, T.J.; Zhu, J.M. Regulatory Mechanisms and Clinical Applications of the Long Non-Coding RNA PVT1 in Cancer Treatment. Front. Oncol. 2019, 9, 787. [CrossRef]

35. Ogunwobi, O.O.; Kumar, A. Chemoresistance Mediated by ceRNA Networks Associated with the PVT1 Locus. Front. Oncol. 2019, 9, 834. [CrossRef] [PubMed]

36. Conte, F.; Fiscon, G.; Chiara, M.; Colombo, T.; Farina, L.; Paci, P. Role of the Long Non-Coding RNA PVT1 in the Dysregulation of the ceRNA-ceRNA Network in Human Breast Cancer. PLoS ONE 2017, 12, e0171661. [CrossRef]

(C) 2020 by the authors. Licensee MDPI, Basel, Switzerland. This article is an open access article distributed under the terms and conditions of the Creative Commons Attribution (CC BY) license (http://creativecommons.org/licenses/by/4.0/). 